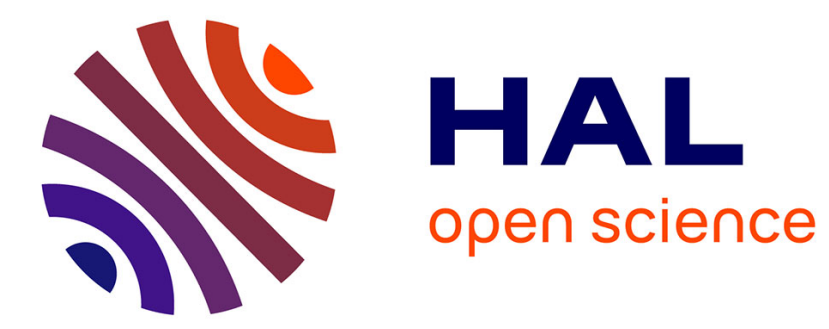

\title{
STRUCTURE, ENERGY AND ATOM MIGRATION EFFECTS OF TILT BOUNDARIES
}

\author{
J. Beeler, Jr, R. Dahl, R. Bourquin
}

\section{To cite this version:}

J. Beeler, Jr, R. Dahl, R. Bourquin. STRUCTURE, ENERGY AND ATOM MIGRATION EFFECTS OF TILT BOUNDARIES. Journal de Physique Colloques, 1975, 36 (C4), pp.C4-97-C4-109. 10.1051/jphyscol:1975411. jpa-00216316

\section{HAL Id: jpa-00216316 https://hal.science/jpa-00216316}

Submitted on 1 Jan 1975

HAL is a multi-disciplinary open access archive for the deposit and dissemination of scientific research documents, whether they are published or not. The documents may come from teaching and research institutions in France or abroad, or from public or private research centers.
L'archive ouverte pluridisciplinaire HAL, est destinée au dépôt et à la diffusion de documents scientifiques de niveau recherche, publiés ou non, émanant des établissements d'enseignement et de recherche français ou étrangers, des laboratoires publics ou privés. 


\title{
STRUCTURE, ENERGY AND ATOM MIGRATION EFFECTS OF TILT BOUNDARIES
}

\author{
J. R. BEELER, Jr. $\left({ }^{*}\right)$, R. E. DAHL, Jr. $\left({ }^{* *}\right)$, and R. D. BOURQUIN $\left(^{* *}\right)$ \\ (*) Materials Engineering Dept., North Carolina State University, \\ Box 5427, Raleigh, North Carolina 27607, U.S.A. \\ (**) Hanford Engineering Development Laboratory \\ Box 1970, Richland, Washington 99352, U.S.A.
}

\begin{abstract}
Résumé. - On rapporte et discute des résultats de calculs sur ordinateur de la structure atomique et des énergies atomiques individuelles pour les cours de joints de flexion de 10 et $40^{\circ}$. Ces résultats sont appliqués à la prédiction de profils de diffusion intergranulaire et de la structure de cour des joints de grains contenant des atomes d'impuretés. On suppose que le fer $\gamma$ peut être représenté par un modèle de métal idéal c. f. c.

Abstract. - Computer experiment results on the atomistic structure of and individual atom energies in $10^{\circ}$ and $40^{\circ}$ tilt boundary cores are given and discussed. These findings are applied to atomic diffusion paths in boundaries and the restructuring of a boundary core by interstitial impurity atoms. An fcc model metal is assumed that is intended to represent gamma-iron.
\end{abstract}

1. Introduction. - This paper describes selected computer experiment results on the nature of $10^{\circ}$ and $40^{\circ}$ tilt boundaries in an fcc model metal intended to represent gamma-iron. It is concerned with boundary structure, boundary energy, and the interactions of point defects with a boundary. Symmetric and asymmetric tilt boundary configurations are considered in (100), (110) and (111) orientations. The physical meaning of this boundary orientation formalism is defined in Section 2. The results for the $10^{\circ}$ boundary cases are characteristic of a boundary that can be modeled as an edge dislocation array and whose energy is described by the Read-Shockley formula. The results for the $40^{\circ}$ boundary cases are characteristic of a boundary that can be conveniently modeled as an array of cavity defects and whose energy is not described by the Read-Shockley formula. These two boundary systems illustrate the main findings obtained in a systematic study [1-3] of $6-84^{\circ}$ asymmetric boundaries in the fcc metal concerned. The range of boundary angles studied was determined by the size of the bicrystal that could be simulated with our computer program at a reasonable cost.

The principal motivation for these tilt boundary computer experiments was to explore the role of grain boundaries in radiation effects processes and the embrittlement of grain boundaries by the accumulation of impurity atoms in a radiation environment. Impurity atom accumulation bears on inert gas atom entrapment, precipitate nucleation, void nucleation, and boundary corrosion. In these connections, the effects of hydrostatic and uniaxial stress were also of interest.

2. Computer experiment method and procedure. - A discrete particle model of an assembly of interacting atoms can be explored by directly computing the motion of each atom in response to the interaction forces exerted on it by other atoms in the assembly. Models containing several thousand atoms have been studied in this way using large-scale, high-speed computers. Such an exploration is called a computer experiment [6]. The types of computer experiment methods that have been used to study discrete particle models are the dynamical, variational and Monte Carlo methods. The particular method used in the present study is the dynamical method, invented by Vineyard's group at Brookhaven National Laboratory [7], wherein the movement of atoms is computed on the basis of Newtonian mechanics. Given an initial set of position and velocity vectors for each atom in an assembly of $N$ atoms, with three degrees of freedom per atom, the $3 N$ simultaneous equations of motion for the assembly are solved numerically. The interaction forces between atoms and the potential energy per atom pair are determined by an assumed pairwise additive potential energy function. Most workers have used central force interaction models. Johnson and Wilson [8] have, in addition, constructed and used non-central force interactions. Most of the potential functions that have been used in computer experiments are empirical functions obtained by fitting various combinations of experimental data. The types of data most commonly used are those for elastic constants, sublimation energy, phonon dispersion relations, defect formation energies, and defect diffusion energies [4].

The static equilibrium configuration for an assembly of $N$ atoms, i. e., that with the lowest potential energy, can be obtained in a dynamical computer experiment by damping out the kinetic energy of every atom in the assembly whenever the kinetic energy of the assembly reaches a maximum. 
This procedure was introduced by Gibson et al. [7]. It is based on the fact that the particle velocity for an oscillator is a maximum when the particle passes through the position of lowest potential energy. This procedure for obtaining the static equilibrium configuration for an atomic assembly is called the quasi-dynamical method.

Grains [1], the computer program used to conduct this study, is a dynamical method program. It builds an (hkl) tilt boundary by overlaying one perfect cubic crystal on another, with a specified rotation angle, $\theta$, and then removing (rejecting) all excess atoms from the bicrystal thus instituted. The building scheme is illustrated in figure 1 for an asymmetric tilt boundary. Each of the two perfect

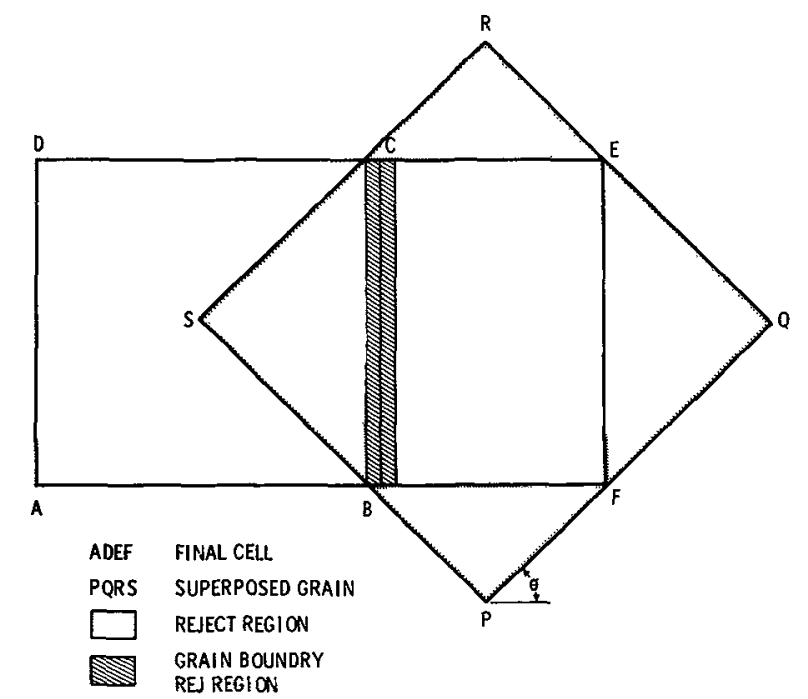

FIG. 1. - Schematic diagram of asymmetric tilt boundary construction by the Grains Program.

crystals is oriented with its (hkl) planes parallel to the plane of the figure. The axis of rotation is the direction [hkl] normal to the plane of the figure. There are two classes of ' excess' atoms. One class consists of the atoms in the superposed crystal region that is designated as the 'Reject Region' in figure 1. The second class of excess atoms consists of those atoms, initially in the superposed crystal, whose presence creates too great an atom density in the region where the two crystals join after the 'Reject Region' alterations have been made. This region is schematically represented in the figure as the 'Grain Boundary Rej Region'. An atom belongs to this class if its distance from neighboring atoms is less than an assigned rejection distance limit designated by Rej. If the separation distance is less than Rej, the atom is rejected. The magnitude of $\operatorname{Rej}$ is not assigned arbitrarily; rather it is established by assuming several different magnitudes and then choosing that particular magnitude that gives the minimum average energy per atom in the bicrystal. The plot from which the magnitude of
Rej is determined is given in figure 2. Construction of a symmetric boundary follows a similar procedure with each crystal being rotated through an angle $\theta / 2$.

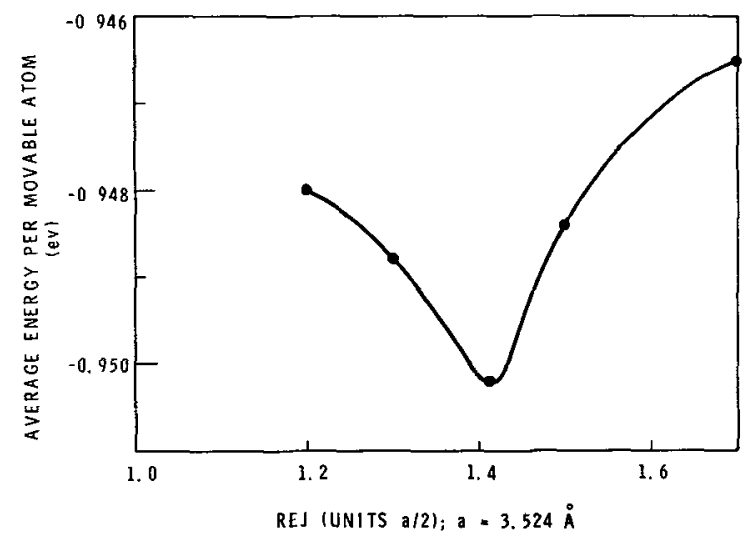

FIG. 2. - The bicrystal energy (average energy per atom) is a function of Rej, the rejection distance. The value of Rej which gave the minimum bicrystal energy was used in a boundary simulation.

Johnson's potential for iron was adopted in the present study along with his iron-carbon potential $[9,10]$. These two potentials are defined in table I and are plotted in figure 3. The neighbor distances marked on the figure are for alpha-iron. In this study, for gamma-iron, the nearest-neighbor distance was $2.578 \AA$ and at that separation distance the atom pair potential energy is $-0.250 \mathrm{eV}$. The cut-off radius $\left(R_{\mathrm{c}}\right)$ for the Johnson iron potential is $3.44 \AA$.

TABLE I

Johnson's iron-iron and iron-carbon potentials

$$
\begin{array}{cc}
\text { Range }(\AA) & \text { Iron Potential }(\mathrm{eV}) \\
- & - \\
0.00-2.40 & -2.195976(\mathrm{r}-3.097910)^{3}+2.704060 \mathrm{r}-7.436448 \\
2.40-3.00 & -0.639230(\mathrm{r}-3.115829)^{3}+0.477871 \mathrm{r}-1.581570 \\
3.00-3.44 & -1.115035(\mathrm{r}-3.066403)^{3}+0.466892 \mathrm{r}-1.547967 \\
\text { Range }(\AA) & \text { Iron-Carbon Potential }(\mathrm{eV}) \\
0.00-2.53 & -3.365(2.236-\overline{\mathrm{r}})^{3}+0.866 \mathrm{r}-2.156
\end{array}
$$

Atom migration was studied by moving the atom concerned toward a vacant site in a systematic stepwise manner and calculating the configurational energy of the bicrystal system at each step. The moved atom was allowed two degrees of freedom, on a plane that was not parallel to the migration path, at each step, so that it could seek out the minimum energy position for the step at hand. In this way, the lowest energy path between the initial atom site and the initially vacant site was traced out. Since the atoms near a boundary core are not regularly arrayed, the migration path usually was not a straight line between the initial and terminal sites of the migrating atom, as it is in a perfect 


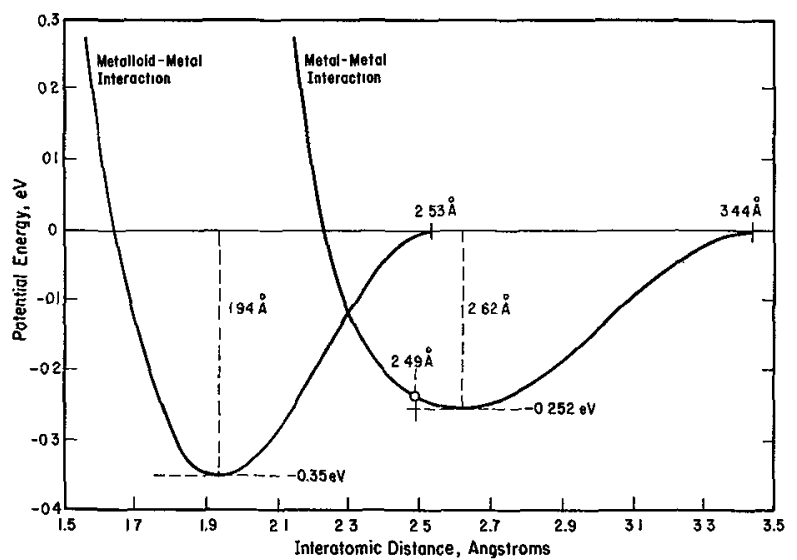

Fig. 3. - Johnson's iron-iron potential (metal-metal interaction) and iron-carbon potential (metalloid-metal interaction).

cubic crystal. The maximum system energy occurring during the migration event corresponds to the saddle point configuration for atom migration. Estimation of the atom migration path and saddle point configuration in irregular atom arrays is an important example of computer experiment utility in materials science and engineering. The activation energy for migration of the atom concerned is the difference between the bicrystal energy for the saddle point configuration and the bicrystal energy when the moved atom is in its normal position.

Migration of an interstitial impurity atom, such as carbon, is treated in the same manner. In this instance, however, the initial and terminal sites for the migration step normally are octahedral sites and the saddle point configuration is a tetrahedral interstitial site configuration. Near a boundary, however, there are perturbations in the nature of the initial and terminal sites, and the migration path is, again, not usually a straight line. The techniques for atom migration calculations have been reviewed by Beeler [6] and by Beeler and Kulcinski [11].

Being a dynamical method program, Grains also is capable of simulating the effects of atom thermal vibrations on boundary structure and energy. Thus far we have used this capability only in subjecting a few boundaries to thermal pulses to test their stability.

3. Tilt boundary energy results. - Dynamical computer experiment boundary energy results for asymmetric (100) tilt boundaries in fcc iron are plotted in figure 4 as a function of the boundary angle, along with the Read-Shockley [12] model results for tilt boundaries. There is agreement with the Read-Shockley model results for angles between $6^{\circ}$ and $15^{\circ}$. The computer experiment results are less than those for the Read-Shockley model between $15^{\circ}$ and $40^{\circ}$, and higher than the Read-Shockley results for angles in the range $40-84^{\circ}$. The central reason for these aspects of agreement and disagreement is that the tilt boun-

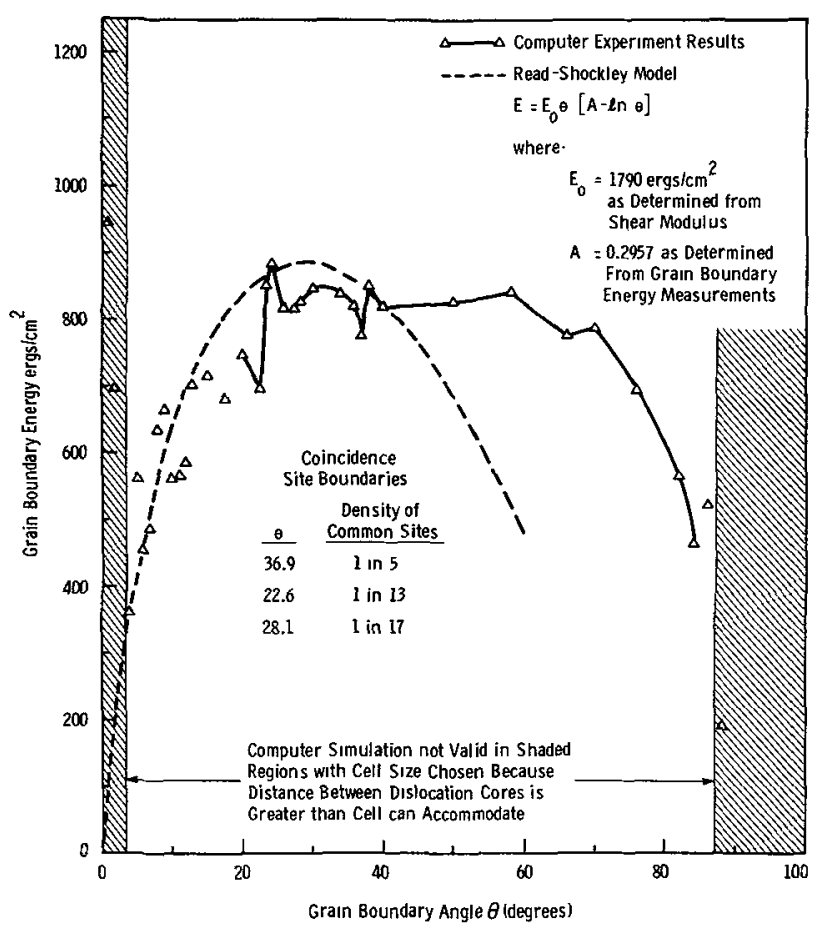

FIG. 4. - Energy of asymmetric (100) tilt boundaries in gamma-iron as a function of the tilt angle, $\theta$.

dary dislocations are sufficiently far apart for the Read-Shockley results to be appropriate for angles up to about $15^{\circ}$, whereas at higher angles, $15-84^{\circ}$, the boundary energetics are complicated by strong interactions among either boundary dislocations or ledges. These interactions are not accounted for in the Read-Shockley formalism. In effect, the theme of this paper centers on a discussion of this simple circumstance and is concerned with a detailed observation of atom configuration and individual atom energy aspects of the core of a tilt boundary. These particular, detailed configurational and energy aspects provide a basis for estimating where a specific impurity atom should position itself in a boundary, and what is the geometrical nature of atom diffusion paths in a boundary. A definition of the tilt boundary core is given in Section 4 .

The results of our previous studies [1-3] on the energies of asymmetric (100) boundaries in gammairon are qualitatively similar to those obtained by Hasson, Biscondi, Lagarde, Levy and Goux [13] in their computer experiments on symmetric (100) boundaries in aluminium. Their results show more detail above $40^{\circ}$ than those plotted in figure 4 . Specifically, they show a cusp at about $53^{\circ}$, an angle not studied in our work. Both explorations indicate that the boundary energy begins to depart from the simple dislocation array model energy formula in the region $15-20^{\circ}$.

Energies of symmetric and asymmetric $10^{\circ}$ and $40^{\circ}$ boundaries, given by our Grains computer experiments, are listed in table II. The $10^{\circ}$ boundaries show a regular behavior as the orientation 
progresses from (100) to (111). In these cases, the boundary energies are ordered as $E_{100}<E_{110}<E_{111}$, and the energy of the asymmetric configuration always exceeds that of the symmetric configuration. Here $E_{\mathrm{hkl}}$ denotes the energy of an (hkl) tilt boundary. In the $40^{\circ}$ boundary cases, a regular ordering, $E_{110}<E_{100}<E_{111}$, occurs within each configurational set, but it is no longer the case that the energy of the asymmetric configuration always exceeds that of the symmetric configuration.

\section{Table II}

Energy of (100), (110) and (111) tilt boundaries in $\mathrm{erg} / \mathrm{cm}^{2}$ for an fcc model metal intended to represent gamma-iron

\begin{tabular}{cccc} 
Boundary & \multicolumn{3}{c}{ Orientation } \\
Configuration & $(100)$ & $(110)$ & $(111)$ \\
- & - & - & - \\
$10 \%$ Symmetric & 464 & 518 & 813 \\
(Case No.) & $(1)$ & $(2)$ & $(3)$ \\
$10 \%$ Asymmetric & 509 & 776 & 1104 \\
(Case No.) & $(4)$ & $(5)$ & $(6)$ \\
$40 \%$ Symmetric & 860 & 827 & 1185 \\
(Case No.) & $(7)$ & $(8)$ & $(9)$ \\
$40 \%$ Asymmetric & 1027 & 819 & 1401 \\
(Case No.) & $(10)$ & $(11)$ & $(12)$
\end{tabular}

For the most part, we will concentrate attention on Case 1, the lowest boundary energy case ; Case 12, the highest boundary energy case; and Cases 8 and 11, which indicate an asymmetric configuration (Case 11), with a slightly lower energy than its symmetric counterpart (Case 8), is the lowest energy $40^{\circ}$ configuration. The motivations for this particular priority of attention are interests in point defect interactions with grain boundaries and in grain boundary corrosion.

Individual atom energies in a tilt boundary show large variations. The distributions of the energy increase per atom in the core of $10^{\circ}$ and $40^{\circ}$ tilt boundaries is given in figures 5-8. Here the energy reference is the potential energy per atom in a perfect crystal. In this regard, the energy increase
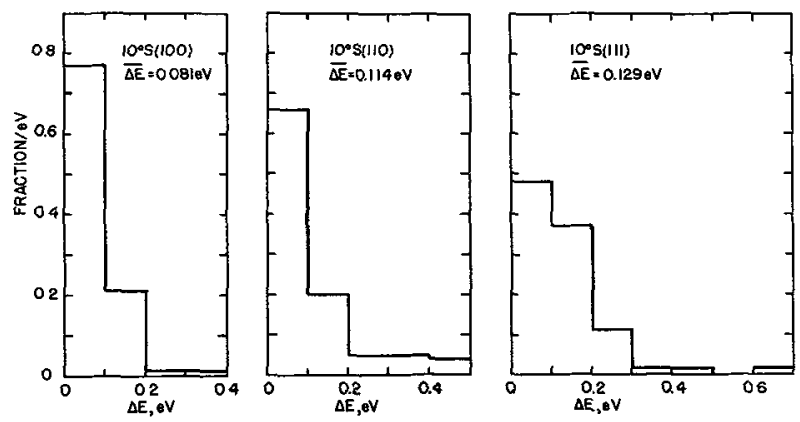

FiG. 5. - Distributions of the energy increase per atom in the core of $10^{\circ}$ symmetric tilt boundaries in gamma-iron. $\Delta E$ is the average increase.
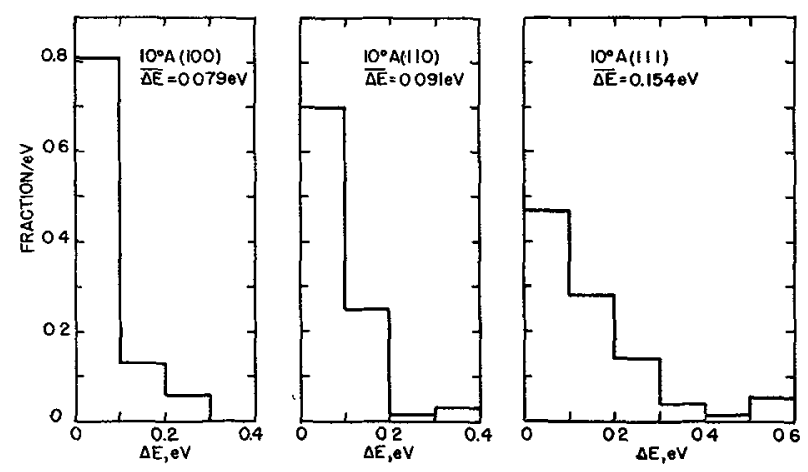

FIG. 6. - Distributions of the energy increase per atom in the core of $10^{\circ}$ asymmetric tilt boundaries in gamma-iron. $\Delta E$ is the average increase.
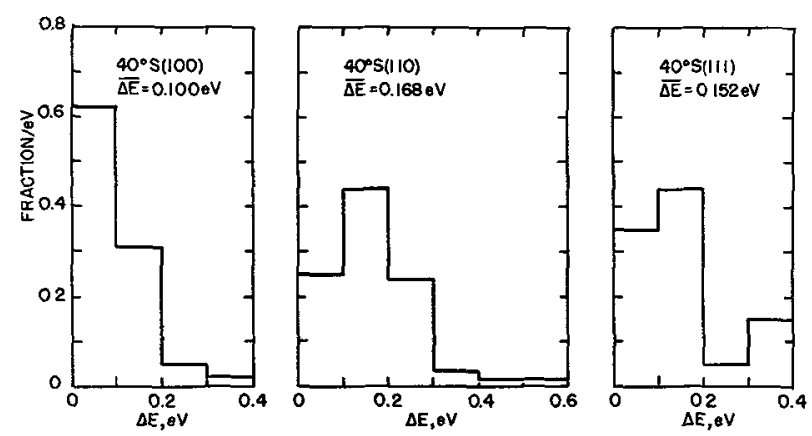

FIG. 7. - Distributions of the energy increase per atom in the core of $40^{\circ}$ symmetric tilt boundaries in gamma-iron. $\Delta E$ is the average increase.
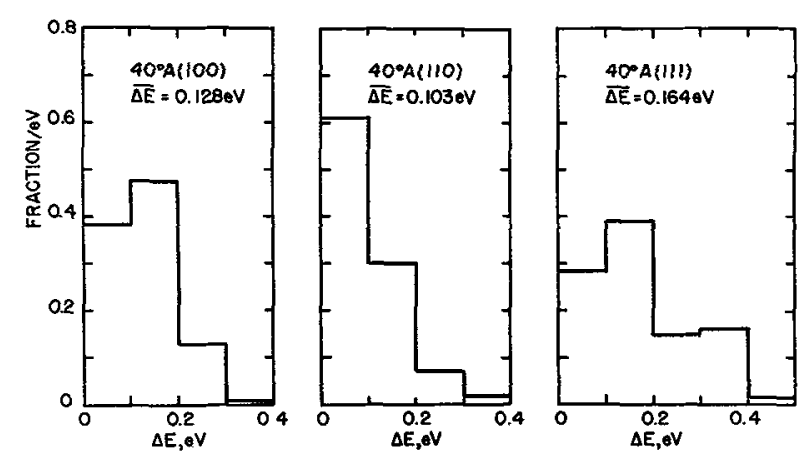

FIG. 8. - Distributions of the energy increase per atom in the core of $40^{\circ}$ asymmetric tilt boundaries in gamma-iron. $\Delta E$ is the average increase.

per atom consists of a primary contribution, due to coordination faults, and a secondary strain energy contribution due to atom relaxations. The relaxations occur in response to the change from the perfect crystal force field to the boundary force field. The force field change is induced by coordination faults.

The average energy increase $\overline{\Delta E}$ for each distribution is cited in the figure label. The notations $10^{\circ} \mathrm{S}(100)$ and $10^{\circ} \mathrm{A}(100)$, for example, denote respectively, a $10^{\circ}$ symmetric and $10^{\circ}$ asymmetric (100) tilt boundary. The ordering of the average energy increase per atom is given in table III. A 
regular ordering occurs within the $10^{\circ}$ symmetric and asymmetric sequences, but it is not true that the symmetric boundary average increase per atom is always less than the asymmetric boundary average increase per atom. In this connection, it is pertinent to recall that, for each $10^{\circ}$ boundary orientation, the boundary energy for the symmetric configuration is less than the energy for the asymmetric configuration. The $40^{\circ}$ average energy increase per atom sequences is irregular; for example, $\overline{\Delta E}_{100}$ is the largest average increase in the $40^{\circ} \mathrm{S}$ sequence, but it is the smallest average increase in the $40^{\circ} \mathrm{A}$ sequence.

\section{TABLE III}

Ordering of the average energy increase $\overline{\Delta E}$ per atom core

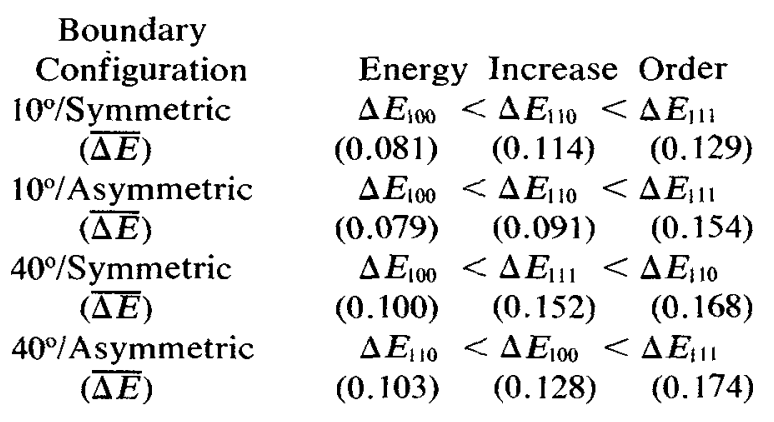

The relative contributions of coordination fault disorder and atom relaxations to the boundary core energy can be read from the core atom energy increase distributions given here. The basis for this useful correspondence is developed in Section 4.

4. Tilt boundary core region. - In this paper, the tilt boundary core region is defined as the region in which the magnitude of the potential energy change per atom, $\Delta E$, is larger than $0.01 \mathrm{eV}$. This energy change is with respect to the potential energy per atom in a perfect crystal. The lower bound on $\Delta E$ in this definition can be raised to $0.05 \mathrm{eV}$ without changing the principal statements in the discussion on core properties. Hence, in effect, the tilt boundary core is regarded as the region in which $\Delta E$ exceeds the thermal energy per atom for temperatures up to $300^{\circ} \mathrm{C}$.

A map of the core of a $10^{\circ} \mathrm{S}(100)$ tilt boundary appears in figure $9 a$. This map shows the relaxed positions of atoms in the core and the energy change per atom. The number pair appearing within an atom symbol states the energy interval, in units of $0.01 \mathrm{eV}$, in which $\Delta E$ for that atom lies. For example, the designation (1-10) means that $0.01<\Delta E \leqslant 0.10 \mathrm{eV}$ for the atom concerned; equality can be associated with the right bound but not the left one. The energy intervals specified in the core map are the same as those used in poten-

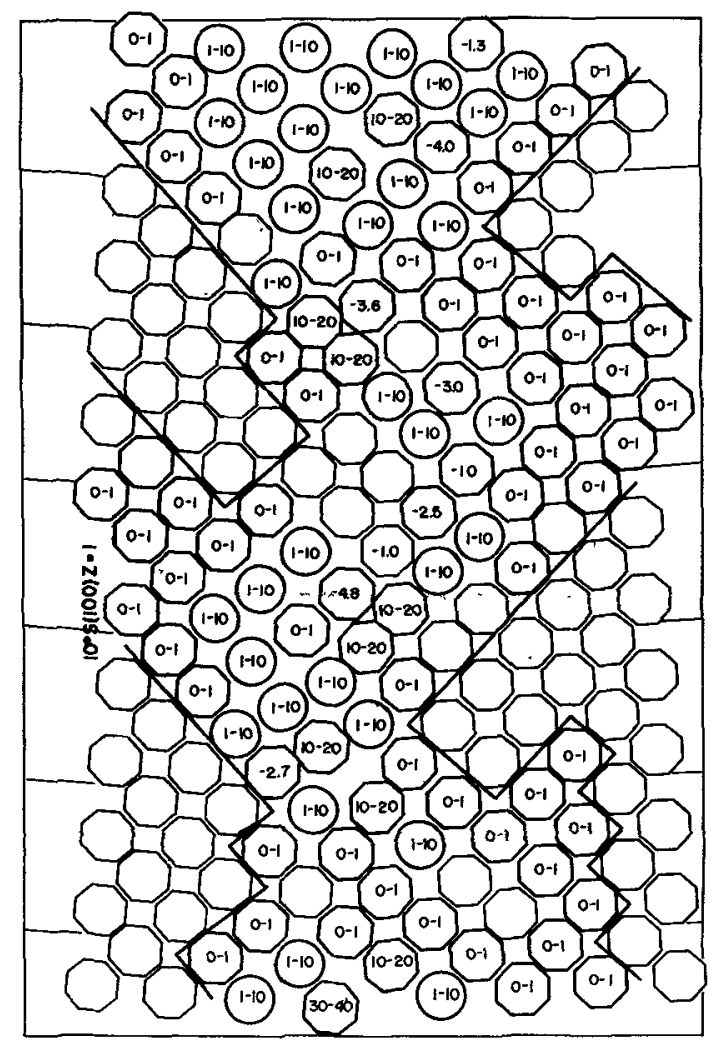

FIG. 9a. -- Map of the energy change per atom in and near the core of a $10^{\circ}$ symmetric (100) tilt boundary in gamma-iron. Symbols and notation are explained in the text.

tial energy increase distribution histograms in figures 5-8. A single number designation, such as - 2.7 , denotes an energy decrease; again the unit is $0.01 \mathrm{eV}$. There are nine such atoms in figure $9 b$. If an atom symbol does not bear a numerical designation, then its energy change lies in the range, $-0.01<\Delta E \leqslant 0 \mathrm{eV}$.

The solid outline in figure $9 a$ marks off the region in which $\Delta E>0$, for nearly all atoms, from the rest of the bicrystal. A circle is used to mark atoms with $\Delta E$ in (1-10) to emphasize that an energy increase usually was associated with the relaxation of these atoms. A energy decrease was associated with the relaxation of any atom designated by an octagon.

An attempt was made to define the energy increase intervals $(1-10),(10-20),(20-30)$ and so forth, so that the occurrence of $\Delta E$ in a specific interval would indicate the principal basis for the increase, i. e., either a decrease in coordination number or a strain energy event. In a perfect crystal of the metal concerned, the nearest neighbor coordination number is $Z=12$ and the structural cohesive energy per atom is $-1.50 \mathrm{eV}$. Hence, a unit decrease in the coordination number corresponds to an energy increase per atom of $0.125 \mathrm{eV}$ prior to relaxation. The degree of cohesive energy recovery during relaxation depends upon the local deployment of neighboring atoms. Ordinarily, about 


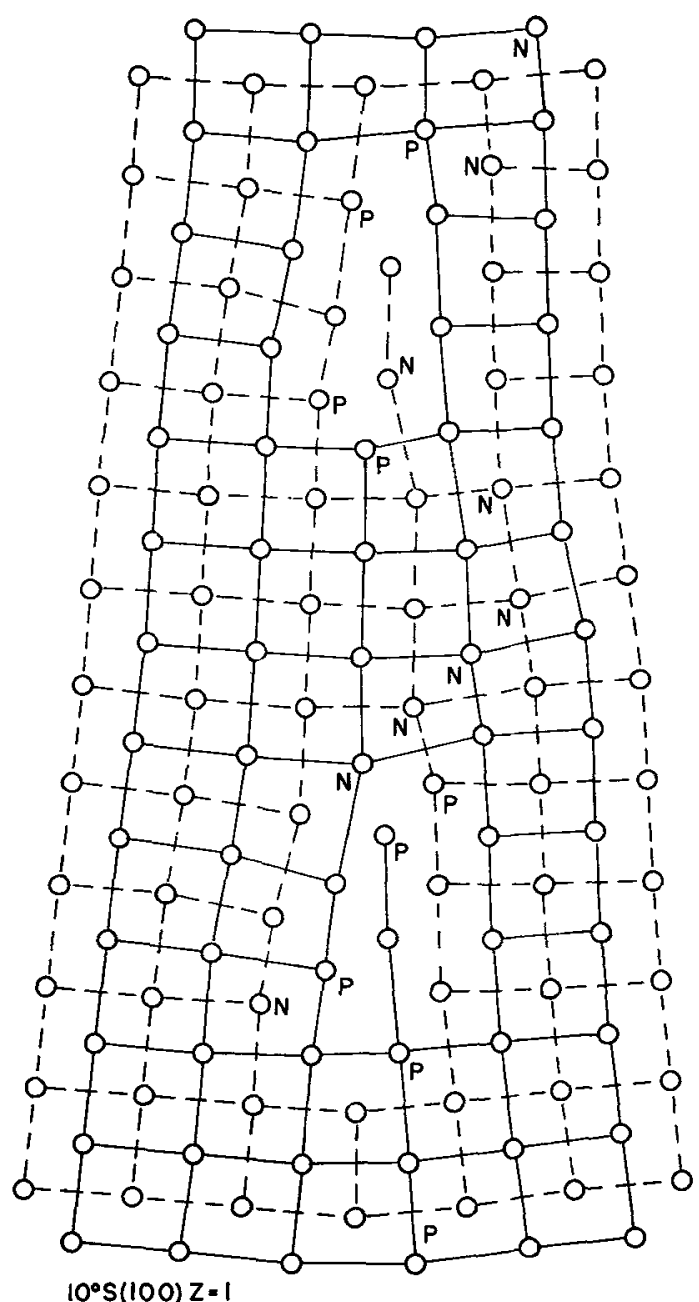

FIG. $9 b$. - Dislocation array structure of the region mapped in figure $9 a$. Atoms marked $P$ showed the largest energy increase ; atoms marked $\mathrm{N}$ the largest amounts of energy decrease. Large relaxations along the boundary (translation) can be seen in the center portion of the figure.

half $(56 \%)$ the energy increase due to a unit decrease in coordination was recovered during relaxation in the boundaries considered here.

During relaxation, the interatomic distance in disordered regions tended toward $2.62 \AA$, the separation distance corresponding to the minimum in the potential function. As a result, the energy per unit coordination was about $-0.125 \mathrm{eV}$. This being the case, a measure of the effective coordination experienced by an atom is,

$$
Z_{\mathrm{e}}=(\text { atom energy }) /(-0.125 \mathrm{eV}) \text {. }
$$

The geometrical coordination number, $Z_{\mathrm{g}}$, for a particular atom counts the number of atoms with which that atom interacts. Specifically, it counts all the atoms with their centers within a sphere of radius $R_{\mathrm{c}}$ centered on the atom of interest, where $R_{\mathrm{c}}$ is the potential function cut-off radius. $Z_{\mathrm{g}}$ is an integer and is larger than $Z_{\mathrm{e}}$. Ordinarily, $\left(Z_{\mathrm{g}}-Z_{\mathrm{e}}\right)$ is about $0.4-0.5$. It is possible for $Z_{\mathrm{g}} \geqslant 12$ in misfit regions. For example, the nine atoms in figure $9 a$ whose energy is less than the perfect crystal atom energy each have $Z_{\mathrm{g}}=13$.

In the case of dislocation array boundaries, atoms with $\Delta E$ in (10-20) typically are either terminal atoms on an edge dislocation extra plane or are located at a corner of an edge dislocation crack wedge. This is illustrated in figure $9 b$. Atoms with $\Delta E$ in (1-10) typically are located in the wall of an edge dislocation crack wedge. For $\Delta E$ in the interval (10-20), the coordination number decrease relative to a perfect crystal ranged from 1-3, prior to relaxation, and from 1-1.5 after relaxation. Most atoms for which $\Delta E$ lies in the interval (1-10) suffered a coordination number decrease of 0.1-0.6 during relaxation. In about one out of six (1-10) instances, however, the atom concerned initially suffered a coordination number decrease of 1-2, and then made a cohesive energy recovery of greater than average magnitude during relaxation.

The energy increase map (Fig. $9 a$ ) for the $10^{\circ} \mathrm{S}$ (100) boundary emphasizes the propagation of local cohesive energy disturbances along close-packed lines. This feature influences atom (vacancy) migration in the vicinity of the core. Quantitative details of this influence on vacancy formation and atom migration are discussed briefly in Section 5 .

An intimate mixing of energy decrease and energy increase regions occurs in the $10^{\circ}$ boundary core. The uncomplicated dislocation structure (Fig. 9b) allows considerable freedom for atom rearrangement in the crack wedge regions. In fact, there is some intrusion of extra atoms into the wedge regions. As mentioned previously, this relaxation freedom in the vicinity of the wedge enables a significant fraction of the core atoms to experience interactions with 13 neighboring atoms. The atoms marked $P$ in figure $9 b$ have $\Delta E$ in (10-20) and those marked $N$ have $\Delta E$ in the interval, $-0.05<\Delta E \leqslant-0.01 \mathrm{eV}$.

In figure 10 , the core atoms per se are presented for the $10^{\circ} \mathrm{S}$ (100) boundary. Nearly all atoms inside the solid outline have $\Delta E>0.01 \mathrm{eV}$. Dashed line octagons represent the exceptions. Squares represent atoms in the $z=2$ plane and the octagons those in the $z=1$ plane of the two-plane set which generates a (100) system in an fcc crystal. The energy increase distributions in Section 3 pertain to the atoms in this restricted region for which $\Delta E>0.01 \mathrm{eV}$. In all but one instance, the boundary core energies (energy per unit area) show the same ordering as the boundary energies. The exception is the $40^{\circ} \mathrm{S}$ sequence for which,

$$
\begin{gathered}
E_{100}<E_{100}<E_{111} \quad\left(40^{\circ} \mathrm{S} \text { Boundary }\right) \\
E_{100}^{\mathrm{c}}<E_{110}^{\mathrm{c}}<E_{111}^{\mathrm{c}} \quad\left(40^{\circ} \mathrm{S} \text { Boundary Core }\right)
\end{gathered}
$$

The core energies, $E_{\mathrm{hkl}}^{\mathrm{c}}$, were computed on the basis of the average energy increase per atom given by the histograms in Section 3. 


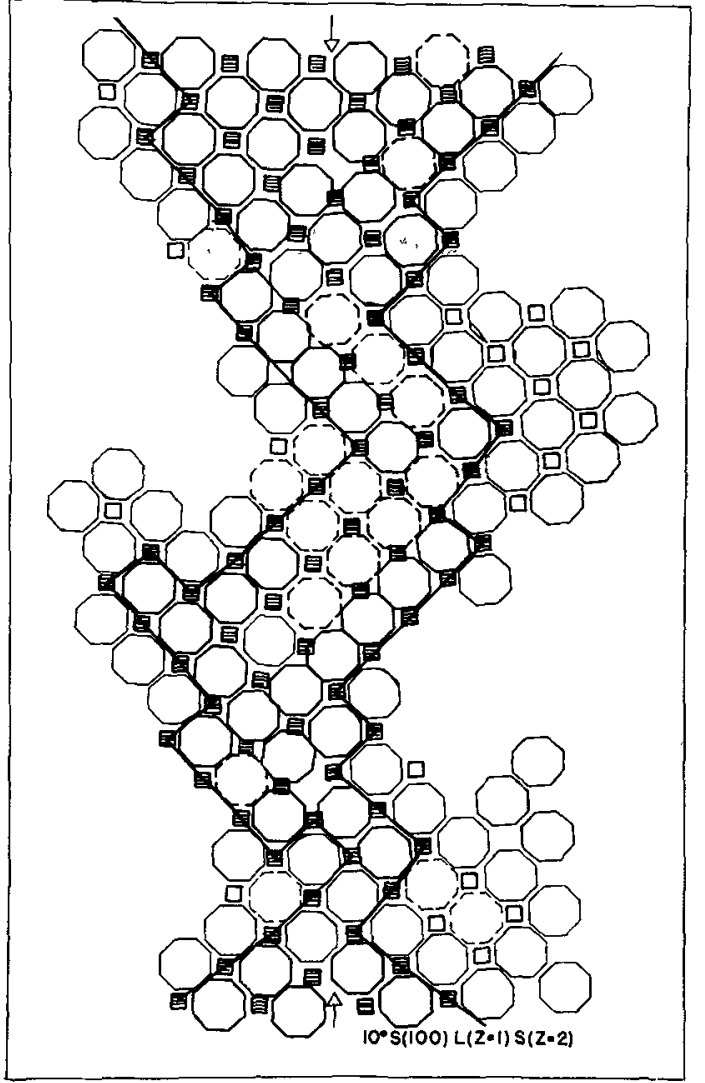

FIG. 10. - The outlined region is the core of the $10^{\circ} \mathrm{S}(100)$ boundary mapped in figure $9 a$ (See text).

The $40^{\circ} \mathrm{A}$ (111) boundary exhibited the largest energy of the 12 boundaries concerned in this section. An energy increase map for this boundary appears in figure $11 \mathrm{a}$. Relative to the $10^{\circ} \mathrm{S}(100)$ map, one notices the absence of atoms with $\Delta E<-0.01 \mathrm{eV}$ and a preponderance of $\Delta E$ in the (20-30) intervals. The atomic interaction between the two bicrystals in the $z=2$ plane of this boundary are described in figure $11 b$. Atoms marked A coordinate across the gap with three atoms in the adjoining crystal; those marked $B$ coordinate with two atoms and those marked $\mathrm{C}$ coordinate with only one atom. There are no wedge regions to allow as much cohesive energy recovery during relaxation in the $40^{\circ} \mathrm{A}$ (111) boundary, as was the case in the $10^{\circ} \mathrm{S}(100)$ boundary. As a consequence, the contact atoms in the core have a low effective coordination in the range $8.5<Z_{\mathrm{e}}<11$. The coordination range for contact atoms in the $10^{\circ} \mathrm{S}(100)$ boundary is $10.5<Z_{\mathrm{e}}<11$. A correspondence between the effective coordination number for a core atom and its $\Delta E$-interval is given in table IV for a $10^{\circ}$ and a $40^{\circ}$ boundary along with a nominal $Z_{\mathrm{e}}$ that is a good approximation for both $10^{\circ}$ and $40^{\circ}$ boundaries.

The lowest energy $40^{\circ}$ boundaries had a (110) orientation and the asymmetric configuration energy was slightly less $(1 \%)$ than that of the

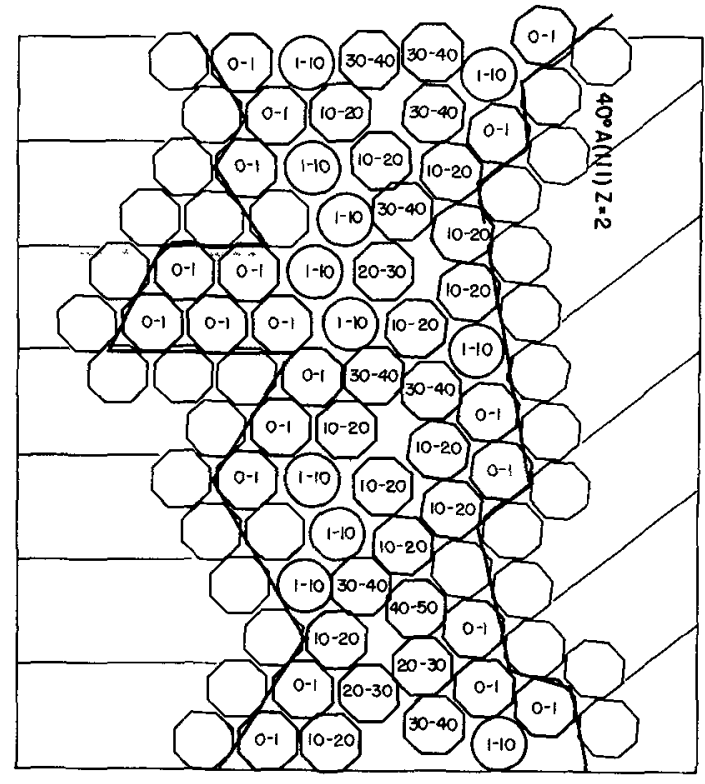

FIG. 11a. - Map of the energy change per atom in and near the core of a $40^{\circ}$ asymmetric (111) tilt boundary in gamma-iron.

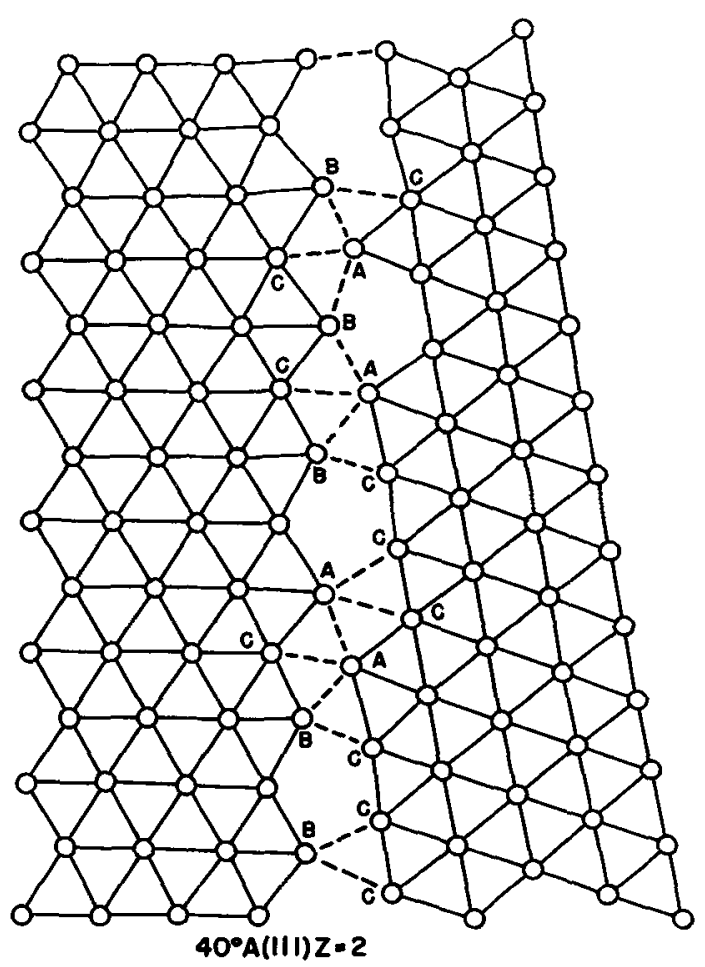

FIG. 11b. - In-plane coordination of the contact atoms in the $40^{\circ} \mathrm{A}$ (111) boundary region shown in figure $11 \mathrm{a}$. Atoms marked A coordinate with three atoms in the other crystal. Those marked B coordinate with two atoms; those marked C coordinate with only one atom.

symmetric configuration. Both of these boundaries have a cavity defect array structure. This type of structure was first suggested by Levy [14].

The energy change map for the $z=2$ plane of the $40^{\circ} \mathrm{A}(110)$ boundary is given in figure 12 . It shows a clean open core structure consisting of a line of 


\section{TABLE IV}

Correspondence between the effective coordination number $Z_{\mathrm{e}}$ and the energy increase per atom intervals for a core atom

\begin{tabular}{cccc} 
& \multicolumn{2}{c}{$Z_{\mathrm{e}}$} & Nominal \\
& \multicolumn{2}{c}{-} & $Z_{\mathrm{e}}$ \\
Interval & $10^{\circ} \mathrm{S}(100)$ & $40^{\circ} \mathrm{A}(111)$ & - \\
- & - & -11.11 .9 & 11.6 \\
$(1-10)$ & $11.4-11.9$ & $11.4-11$ & 10.7 \\
$(10-20)$ & $10.5-11.0$ & $9.0-11.1$ & 10.1 \\
$(20-30)$ & - & $9.9-10.3$ & 10.1 \\
$(30-40)$ & - & $8.5-9.4$ & 9.1 \\
$(40-50)$ & - & 8.3 & 8.3
\end{tabular}

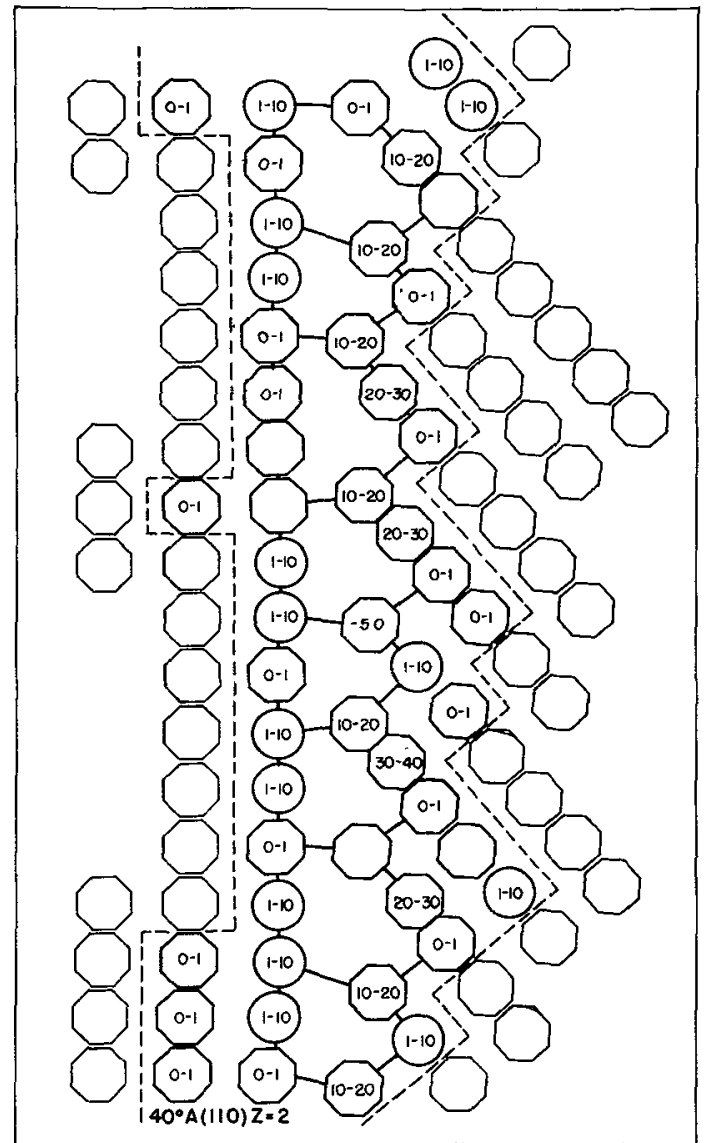

FIG. 12. - Cavity array structure of a $40^{\circ} \mathrm{A}$ (110) boundary.

cavities. The presence of a $\Delta E=-5.0$ and only one $\Delta E$ in the (30-40) interval indicates, however, that $Z_{\mathrm{e}}$ is relatively large. The map for the adjacent $z=1$ plane in figure 13 shows why $Z_{\mathrm{e}}$ is relatively large. Each cavity in the $z=2$ plane is accorded a roof and floor by atoms in the adjoining (110) planes. These cavities provide ample relaxation freedom for atoms in the boundary core, just as did the crack wedges in the $10^{\circ} \mathrm{S}(100)$ core. A count of the number of atom symbols within each pentagonal outline in figure 13 provides a good measure, in atomic volumes, of the cavity size. Utilizing

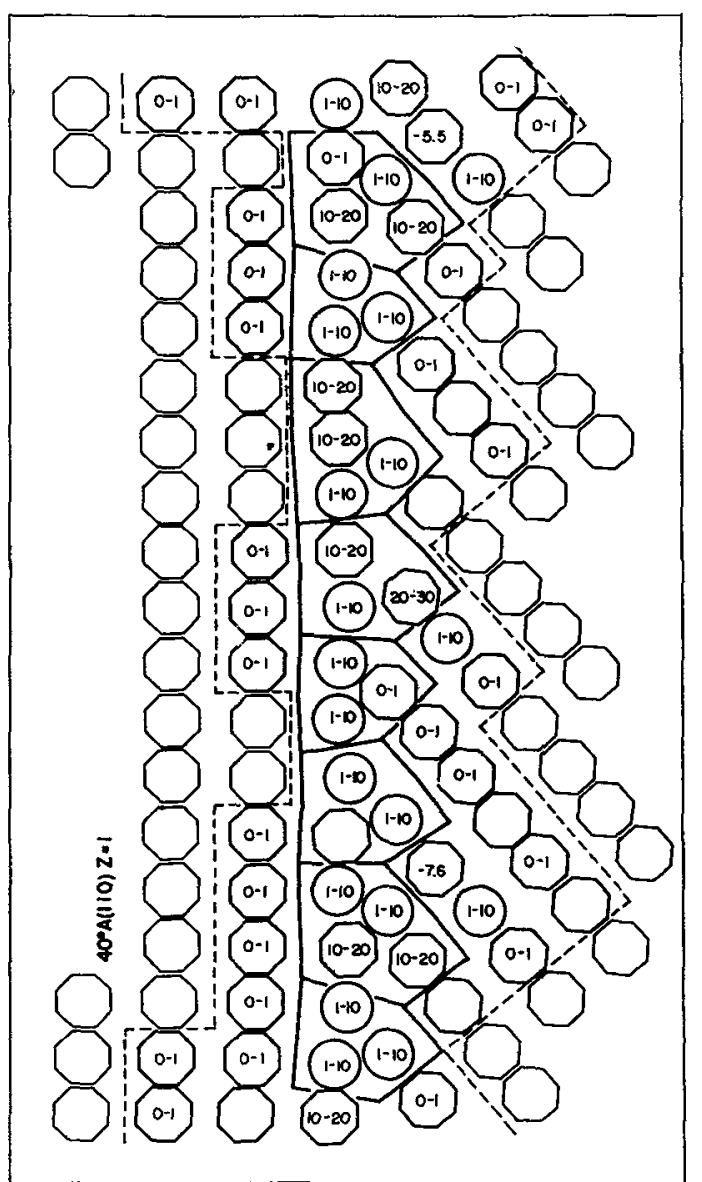

FIG. 13. - Cavity array structure of a $40^{\circ} \mathrm{A}$ (110) boundary.

table IV, one can estimate $Z_{\mathrm{e}}$ for each atom in the core. Atom positions in both planés are shown, superposed, in figure 14 . The large symbols correspond to the $z=2$ plane and the small symbols to the $z=1$ plane.

The structure of the $40^{\circ} \mathrm{S}$ (110) boundary is qualitatively the same as that for the asymmetric boundary; this is illustrated in figure 15 . In this instance, the location of the cavities changes back and forth from the $z=1$ to the $z=2$ planes. All of the cavities were located in one subset of planes in the asymmetric boundary.

These cavity structure boundaries would provide storage space for helium atoms in neutronirradiated austenitic steel. In addition, they provide a catalytic surface with a variety of ledge shapes and angles for either precipitate nucleation or corrosion reactions. To the best of our knowledge, no systematic computer experiment work has been done to explore the role of cavity array structures in precipitation and corrosion processes. The mechanical properties of cavity array structures also remain to be explored. We have done a few computer experiments on atomic diffusion near a cavity line (misfit region) in a $6^{\circ}$ boundary, and on boundary cavity restructuring by carbon impurity atoms. Short accounts of these studies appear in the next two sections. 


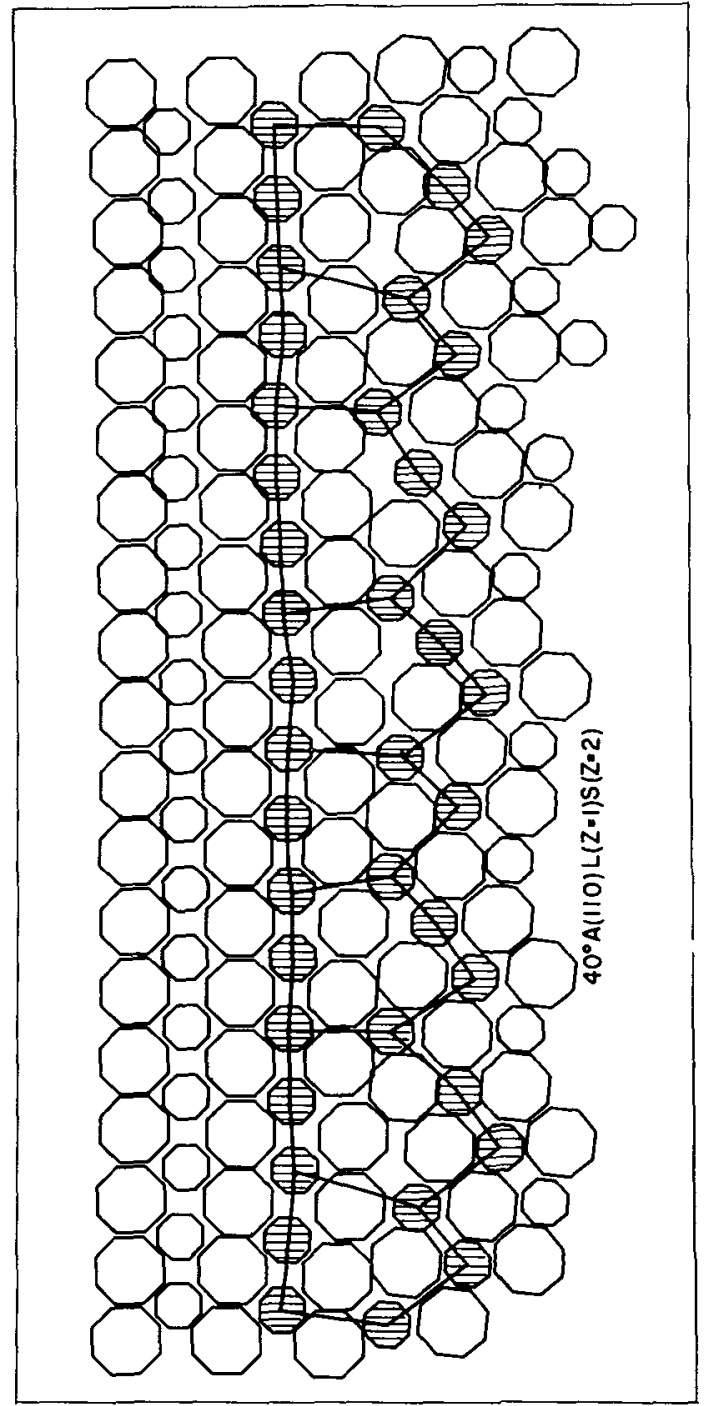

FIG. 14. - Cavity array structure of a $40^{\circ} \mathrm{A}(110)$ boundary.

5. Vacancy formation and migration. - Computer experiments on vacancy formation and migration in and near the core of a tilt boundary should shed light on the mechanism for vacancy emission and absorption at grain boundaries. In addition, they are useful tools for exploring atom migration paths in and near a grain boundary. The vacancy formation energy, $E_{\mathrm{f}}^{v}$, is the change in crystal energy when an atom is removed from the interior of the crystal and placed on a rough surface in such a manner that the surface area does not change but the crystal volume does change (increase). The vacancy migration energy, $E_{m}^{v}$, is the height of the energy barrier encountered when an atom and a first-neighbor vacancy to this atom exchange positions. Vacancy formation and migration energy studies were made for low and high angle boundaries. The results for a $6^{\circ} \mathrm{A}(100)$ boundary are both representative and easy to discuss from a geometrical standpoint. A map of atom positions in the $z=4$ plane of a $6^{\circ} \mathrm{A}(100)$ boundary is given in

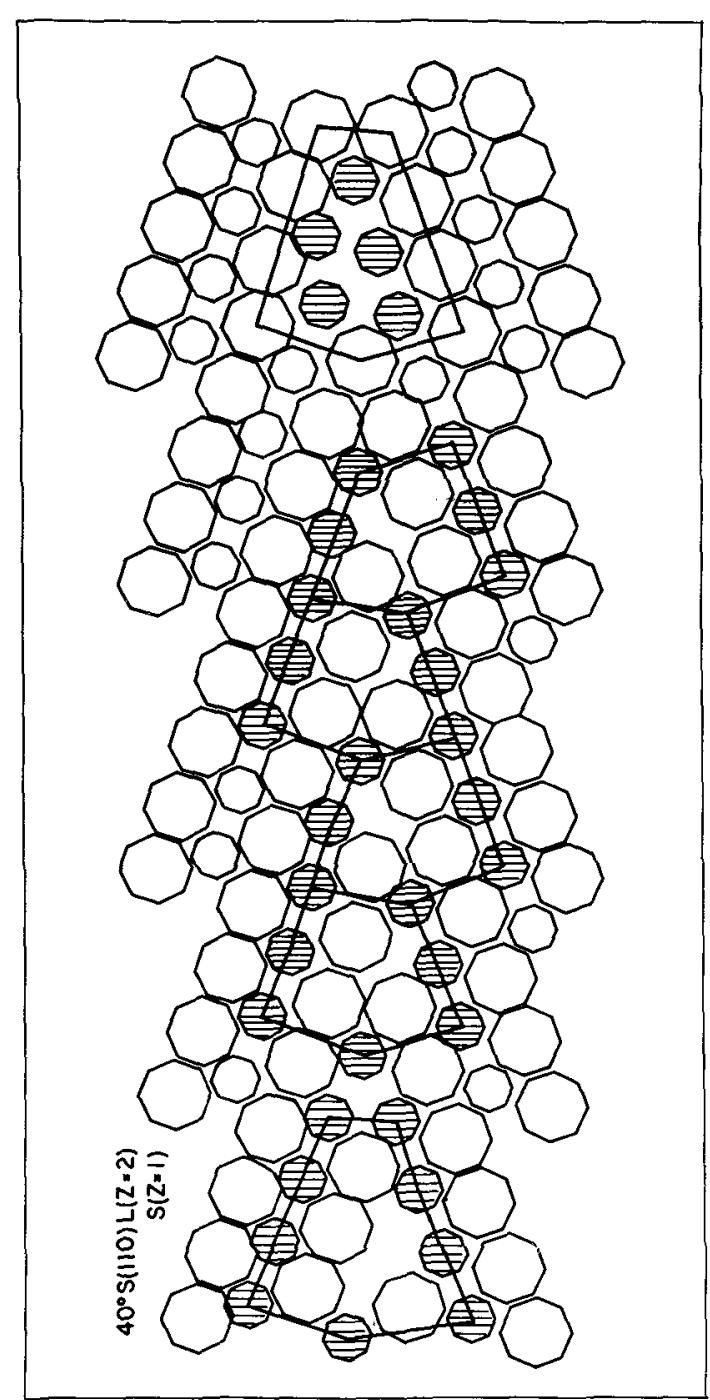

FIG. 15. - Cavity array structure of a $40^{\circ} \mathrm{S}$ (110) boundary.

figure 16. The number in each atom symbol is its index in the Grains bicrystal computational cell. Vacancy formation energy results for sites in the core of this boundary are summarized in figure 17. The vacancy formation energy in an initially perfect crystal of the metal concerned is $1.5 \mathrm{eV}$. No direct correlation exists between the magnitude of the formation energy and $Z_{\mathrm{c}}$ for the atom removed. This is true because indirect relaxation effects, not directly determined by $Z_{\mathrm{e}}$, play a major role in establishing the formation energy.

Figure 18 shows the bicrystal energy variation as atom 402 is moved into a vacant site at 407 and the converse, as atom 407 is moved into a vacant site at 402. Only $0.01 \mathrm{eV}$ is required to move the vacancy from 407 to 402 . The reverse process requires an activation energy of $1.56 \mathrm{eV}$. This activation energy exceeds the vacancy formation energy because the cohesive energy recovery process at a boundary is less efficient than that at a rough free surface. The vacancy migration energy in the bulk is $1.32 \mathrm{eV}$ for 


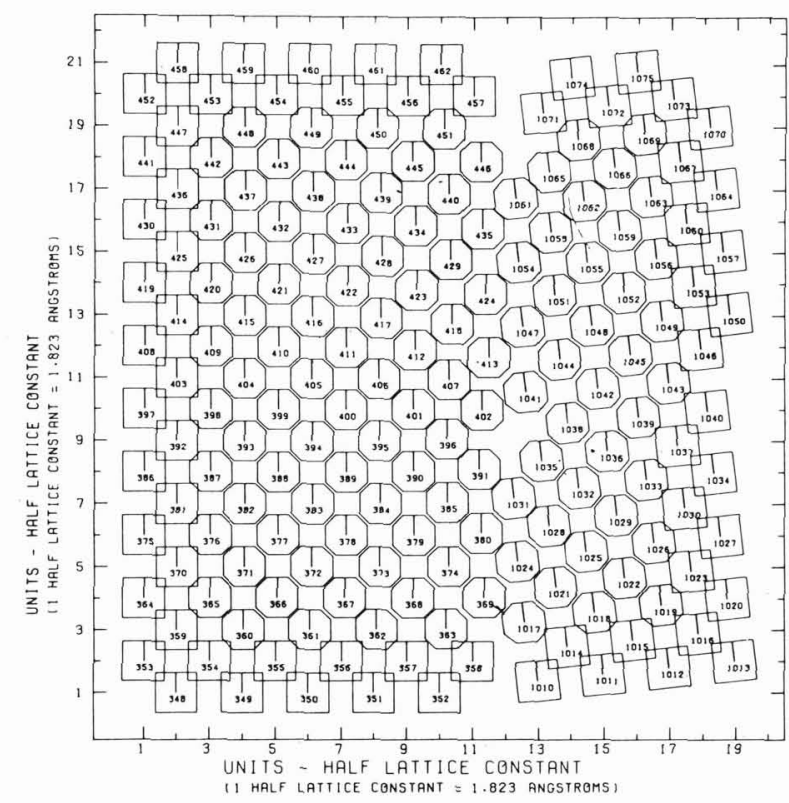

FIG. 16. - Atom position map for a $6^{\circ}$ asymmetric (100) tilt boundary in gamma-iron.

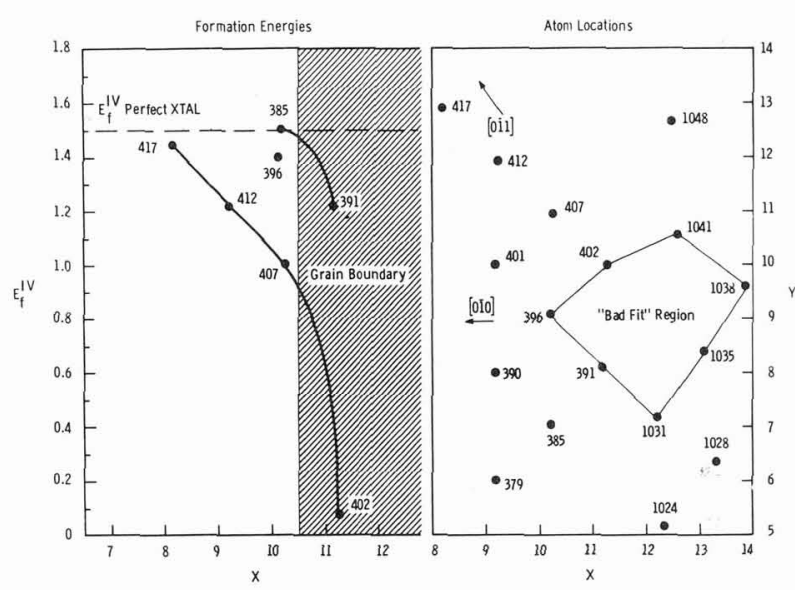

FIG. 17. - Vacancy formation energy in and near the $6^{\circ} \mathrm{A}(100)$ boundary shown in figure 16.

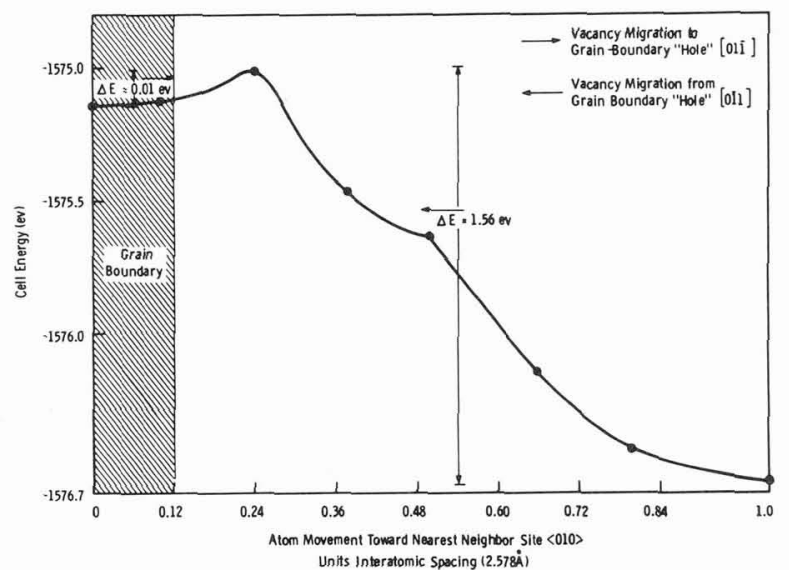

FIG. 18. - Vacancy migration energy from site 407 to site 402 (bad fit region) in figures 16 and 17. the metal concerned. On the basis of vacancy migration energy results along close-packed lines to a free surface [15], one would expect the activation energy for the movement of a vacancy from site 412 to site 407 to be about $1.03 \mathrm{eV}$, and that for vacancy movement from site 417 to 412 to be the bulk crystal value, $1.32 \mathrm{eV}$.

Auxiliary computer experiment results [16] indicate that atom migration paths parallel to the core of a boundary should run along close-packed line segments that pass through sites located one or two interatomic distances from the core wall rather than on the core wall. For paths through such sites, the vacancy migration energy is $80-90 \%$ of that for paths on the core wall and is $68-77 \%$ of the vacancy migration energy in bulk material. An assessment of what this means with respect to the magnitude of the grain boundary diffusion coefficient depends upon the local cycle of vacancy emission and absorption at a boundary. This is true because the average vacancy concentration on the path sites concerned depends on this cycle. Our vacancy formation energy results indicate vacancy formation energies at these sites that are $67-80 \%$ of the vacancy formation energy in the bulk. If one assumes the smallest activation energies possible, on these grounds, an activation energy of $1.9 \mathrm{eV}$ is indicated for diffusion in a tilt boundary. James and Leak [17] measured an activation energy of $1.7 \mathrm{eV}$ for diffusion in gamma-iron grain boundaries. They obtained the ratio $Q_{\mathrm{gb}} / Q_{v}=0.56$ where $Q_{\mathrm{gb}}$ and $Q_{v}$ are the activation energies for grain boundary and volume diffusion, respectively. Our results give $Q_{v}=2.82 \mathrm{eV}$ and $Q_{\mathrm{gb}} / Q_{v}>0.67$. One would expect the quantitative agreement between the computer experiment results and laboratory results to improve if a longer range potential function model were adopted. As it stands, however, the firstneighbor interaction model gives a credible qualitative description of the atom migration process near a boundary.

6. Effect of carbon atoms on tilt boundary structure. - Small concentrations of interstitial impurity atoms can produce large effects on the properties of metals. Of these impurities, which include boron, nitrogen, hydrogen and carbon, carbon is perhaps the most important, particularly in ferrous alloys. A detailed account of our work on the effect of carbon has been presented previously [2] ; in this section only a brief account of the major effects will be stated.

When a carbon atom was inserted in the bad fit region of a $6^{\circ} \mathrm{A}$ (100) boundary, as defined by figures 16 and 17 , the boundary structure became well-ordered, as shown in figure 19. The carbon atom is represented by a triangular symbol below atom 402. The indirect relaxation response to the local knitting together of the bad fit region around the carbon atom resulted in a more regular boun- 
dary structure. The energy of the bicrystal was reduced by about $2.6 \mathrm{eV}$; of this, about $1.6 \mathrm{eV}$ can be attributed to lattice relaxation into a more stable configuration. The remaining $1 \mathrm{eV}$ resides with the carbon atom as bond energy. The ordering or healing of a grain boundary, as described, would certainly facilitate the transmission of strain from one grain to another. This would enhance ductility.

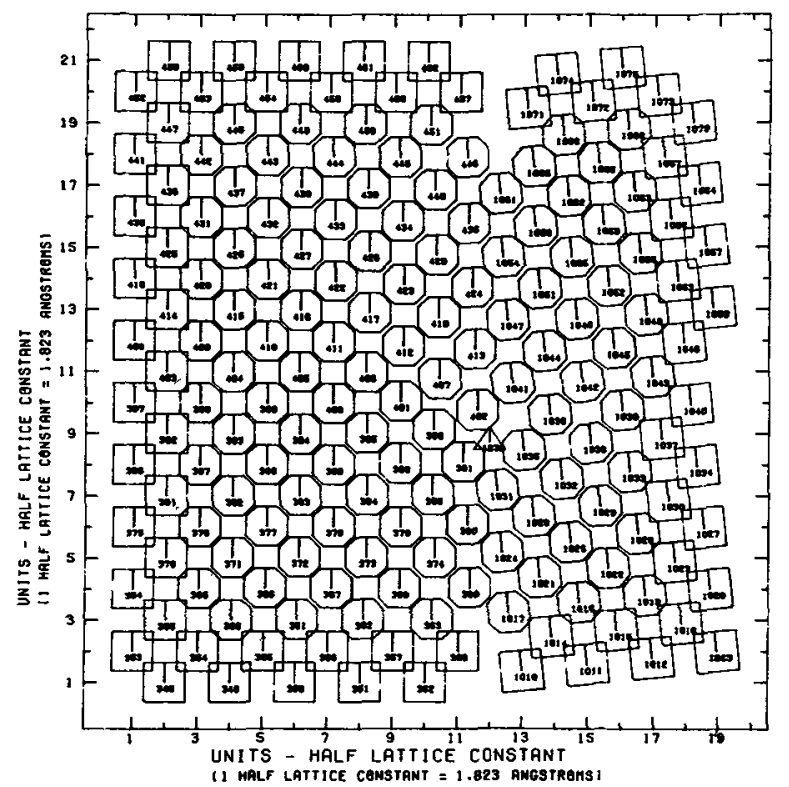

FIG. 19. - Restructuring of a $6^{\circ} \mathrm{A}(100)$ boundary by a carbon impurity atom. The triangular symbol represents the carbon atom. Comparison of this figure with figure 16 shows the healing effect of the carbon atom.

When clusters of several carbon atoms were introduced, a local region developed that had a greater cohesive energy per atom than the host metal. This circumstance, the nucleation of a precipitate, acts to impede the transmission of strain and induces embrittlement. These features of carbon atom interaction with the boundary suggest that improved ductility should occur for carbon concentrations sufficiently low that cluster formation is improbable, and that embrittlement should occur at higher carbon concentrations.

7. Summary and conclusions. - From the standpoint of boundary structure, the results obtained using the dynamical method are similar to those obtained by Weins et al. [18] and Hasson et al. [13], using the variational method, for both symmetric and asymmetric configurations. Attainment of the minimum energy configuration by translation along the boundary, first pointed out by Chalmers and Gleiter [19], occurred as a natural consequence of the atom rejection and relaxation process in our dynamical method computer experiments.

The results of our exploratory work on atomic migration in and near a boundary, and on the restructuring of a boundary by impurity atoms, suggest that dynamical method computer experiments on precipitation, corrosion and catalysis in cavity array structures should be technologically useful. The fact that the dynamical method allows one to simulate the effects of atom thermal vibrations [1] and of applied stress makes it an especially attractive means for exploring certain atomistic aspects of creep and grain boundary movement.

Acknowledgement. - Most of the auxiliary simulations of atom migration near a boundary misfit region were done by Mary $F$. Beeler.

This paper is based on work performed by the Hanford Engineering Development Laboratory, Richland, Washington, operated by the Westinghouse Hanford Company, a subsidiary of Westinghouse Electric Corporation, for the United States ERDA Contract AT45-1-2170 [Dahl and Bourquin]; and by the North Carolina State University for the United States ERDA Contract AT40-1-3912 and Air Force Materials Laboratory Contract F33615-68-C-1012 [Beeler].

\section{References}

[1] Dahl, R. E. Jr., Beeler, J R. Jr. and Bourquin, R. D., Comput. Phys. Commun. 2 (1971) 301.

[2] Dahl., R. E. Jr., Beeler, J. R. Jr. and Bourquin, R. D., Grain Boundaries in Gamma-Iron and Their Interactions with Point Defects, pp 673-694 in reference 4.

[3] Dahl, R. E. Jr., Beeler, J R. Jr. and BovRquin, R. D., Asymmetric Grain Boundaries and Their Interaction with Vacancies and Carbon Atoms, pp. 123-151 in reference 5

[4] GEHLEN, P. C., BEELER, J. R. Jr. and JAFFEE, R. I., editors, Interatomic Potentials and Simulation of Lattice Defects (Plenum Press) 1972.

[5] Hu, H., editor, Nature and Behavior of Grain Boundaries (Plenum Press) 1972.

[6] BeEl.er, J. R. Jr., Computer Experiments in Materials Research, pp. 295-476, in Advances in Materials Research, H. Herman, editor (Interscience) 1970, vol. 4.

[7] Gibson, J B., Goland, A. N., Milgram, $M$ and Vineyard, G. H., Phys. Rev. 120 (1960) 1229.

[8] Johnson, R. A. and Wilson, W. D., Defect Calculations for FCC and BCC Metals, pp. 301-319 in reference 4.
[9] JOHnSON, R. A., Phys. Rev. 134 (1964) A1329.

[10] Johnson, R. A., Dienes, G. J. and Damask, A. C., Acta Met. 12 (1964) 1215.

[11] Beeler, J. R. Jr. and Kulcinski, G. L., Comput. Techniques, pp. 735-751 in reference 4.

[12] Read, W. T. and Shockley, W., Phys. Rev. 78 (1950) 275.

[13] Hasson, G., Biscondi, M., Lagarde, P., LeVy, J. and Goux, C., Structure of Grain Boundaries, pp. 3-40 in reference 5 .

[14] LeVY, J., Phys. Stat. Sol. 31 (1969) 193.

[15] BEELER, J. R. Jr., Interactions of Vacancies and Interstitials with Free Surfaces and Grain Boundaries, International Conference on Vacancies and Interstitials in Metals, Kernforschungsanlage, Julich, Germany, vol. 2 (1968) 598.

[16] BEeler M. F. and BEeler, J. R. Jr, Unpublished work.

[17] James, D. W. and Leak, G. M., Phil. Mag. 12 (1965) 491.

[18] Weins, M. J., Gleiter, H. and Chalmers, B., J. Appl. Phys. 42 (1971) 2639.

[19] Chalmers, B. and Gleiter, H., Phil. Mag. 23 (1971) 1541. 


\section{DISCUSSION}

F. HAESSNER : Is it possible to get the activation entropy of grain boundary self diffusion in your dynamic approach? If yes, are these values very sensitive to the orientation parameters of the boundary?

J. R. BEELER: It is possible to estimate the entropy associated with the movement of individual atoms, in our approach, if you are welling to accept the Huntington approximation. However, we have not done this for grain boundaries so I cannot comment on the orientation dependence.

E, D. Hondros: You have made a nomber of comments relating on open structure at the grain boundary to brittleness : do you mean to say that cohesion at the grain boundaries can be related to the type of structure in this simple manner?

\section{J. R. BEELER : No.}

K. LUCKE : My question is concerned with grain boundary migration perpendicular to its area. Is the dynamic method able to detect which is the mechanism(s) of this motion, in particular, which atoms tend to switch over to the other crystal and which is the sequence of such atom movements ? Should it be possible to investigate by this method the true boundary migration by applying in Newton's equation for the boundary atoms an additional driving force?

J. R. BEELER : The local atom movement sequences can be investigated using the GRAINS program as it is presently programmed. Bodily movement of the entire boundary in response to a driving force can not be simulated without altering the program. In brief, all the items you mention can be accomplished using the dynamic method.

P. PUMPHREY : Your $40^{\circ}$ boundaries lie between high density (short period) CSL boundaries. Experimental measurements indicate that they should differ rather little in energy from boundaries with slightly different misorientations. Do you find that the minimium in energy corresponding to the equilibrium structure is rather ill defined?

J. R. BEELER: The minimium is not ill defined. Figure 2.2 indicates the quality of definition.

B. RALPH : It seems to me that there would be a large advantage in assuming the overall boundary geometry prior ro beginning your dynamic computations. Might I suggest that a geometrical picture, such as that which arises from the Bollmann « $0 »$ and DSC descriptions, would allow the computation of a larger volume of material. In considering the interaction between matrix and boundary region this would have considerable advantages.

J. R. BEELER : I agree. We plan to adopt their approach.

D. MC LEAN : As a test of your method of calculation, have you compared the grain boundary energy per unit area given by your calculation with the experimental value?

J. R. BEELER : The agreement is good. Usually to within $10 \%$, always within $20 \%$.

$M^{\text {me }}$ CYROT : J'ai été frappée par le fait que les divers conférenciers de ce matin utilisaient des potentiels interatomiques qui ne faisaient en rien référence à la structure électronique des métaux. Pour les métaux, tels l' $\mathrm{Al}$, le $\mathrm{Cu}, \mathrm{l}^{\prime} \mathrm{Au}$, une méthode de type pseudopotentiel pourrait donner de bons résultats sauf si des variations importantes de volume sont en jeu car l'on sait bien que de tels «potentiels» sont très dépendants du volume.

Pour les métaux de transition, tel le fer, une méthode de liaisons fortes pourrait sûrement être utilisée avec profit car les électrons d sont responsables de la cohésion.

J. R. BEELER : Yes. What you suggest should be done, in my opinion.

D. A. SMITH : Since many calculations of grain boundary structure and energy involve the use of periodic boundary conditions and thus the results can only apply to periodic (i. e. coincidence) boundaries what procedure is used to interpolate between the various coincidence boundaries investigated in order to plot a continuous graph of energy versus misorientation for a particular axis. Should not one take account of the observations by electron microscopy and use a modified ReadShockley calculation in order to describe the energy of boundaries near coincidence orientations in view of the existence of dislocation arrays which presumably conserve the pattern characteristic of the coincidence orientation wether the wishes of the network.

C. Goux: Il n'est pas facile de donner une réponse très sûre à la question posée. Néanmoins, si nous considérons, par exemple, le cas des joints symétriques de flexion de type (o, p, q) dans l'aluminium, les énergies ont été calculées pour une trentaine de joints dont les désorientations sont échelonnées d'environ $3^{\circ}$. Des «cusps » peu accentués apparaissent pour les joints (013) et (012) mais les valeurs des énergies des joints intermédiaires varient de manière régulière et si l'on considère la courbe représentant l'énergie en fonction de la 
désorientation, on ne voit pas comment pourraient s'introduire des cusps tant soit peu prononcés dans des intervalles de la désorientation voisins de $3^{\circ}$.

D. A. SMITH : Vitek, Pond and Smith have investigated the energy of symmetrical $<001>$ and $<011>$ tilt boundaries in aluminium using a pseudopotential fitted to the phonon spectrum and giving values of the intrinsic stacking fault energy of $105 \mathrm{erg} . \mathrm{cm}^{-2}$. Subject to overall volume conservation and preservation of the coincidence orientation but not position (i. e. translations are permitted) the boundary energy is minimised by a steepest gradient method and the energy calculated at the minimium with the potential truncated between the 5th and 6th nearest neighbours. The results suggest only a factor 2 variation in energy between the $\Sigma=5$ and $\Sigma=41<100>$ boundaries and no simple monotonic relationship exists between energy and $\Sigma$ or the size of a repeating unit. We attach significance to our results because of the agreement between predictions and the experimentally measured values of translation for high index orientations of the boundary plane and $\Sigma=3$ twins.

P. LESBATS: Les essais de divers potentiels n'ont pas été jusqu'à maintenant très significatifs, car des potentiels même très différents semblent, à part peut-être quelques cas particuliers, conduire aux mêmes structures et les comparaisons n'ont porté que sur l'énergie à basse température, pour laquelle il est très difficile de faire des mesures précises.

L'énergie est une caractéristique globale des joints qui permet de les classer mais qui ne joue pas un rôle primordial dans beaucoup de phénomènes. Elle est un peu un sous-produit des calculs de structures de joints, dont l'intérêt est de fournir un point de départ pour des modèles qui essaient de rendre compte de la diffusion intergranulaire, de la déformation au joint, etc... et pour lesquels le type de potentiel utilisé risque d'être plus important. 